\title{
Acute Ischemic Stroke in Patients on Treatment with Non-Vitamin K oral Anticoagulants: Safety and Efficacy of NOAC Plasma-Level-Guided Therapy
}

Armin Marsch, MD¹; Kosmas Macha, $\mathrm{MD}^{1}$; Stefan Schwab, MD; Bernd Kallmünzer, MD

${ }^{1}$ Authors contributed equally

Department of Neurology, Universitätsklinikum Erlangen, Friedrich-Alexander-University Erlangen-Nürnberg (FAU), Erlangen, Germany

BACKGROUND: The management of patients with acute ischemic stroke during treatment with non-vitamin $\mathrm{K}$ oral anticoagulants (NOAC) is challenging. Functional NOAC-plasma-levels could guide decisions on therapies.

METHODS: A standard operating procedure for patients on NOAC was established: Patients with a plasma level below $50 \mathrm{ng} / \mathrm{mL}$ were considered eligible for intravenous thrombolysis (IVT), while levels above $100 \mathrm{ng} / \mathrm{mL}$ constituted an exclusion criterion. Levels between 50 to $100 \mathrm{ng} / \mathrm{mL}$ allowed an individual decision (Figure 1). For patients on vitamin-K antagonists (VKA), a cutoff for IVT was set at INR 1.7. Mechanical recanalization (EVT) of a large vessel occlusion was indicated independently from coagulation testing. Consecutive patients were included in an observational registry starting in January 2014.
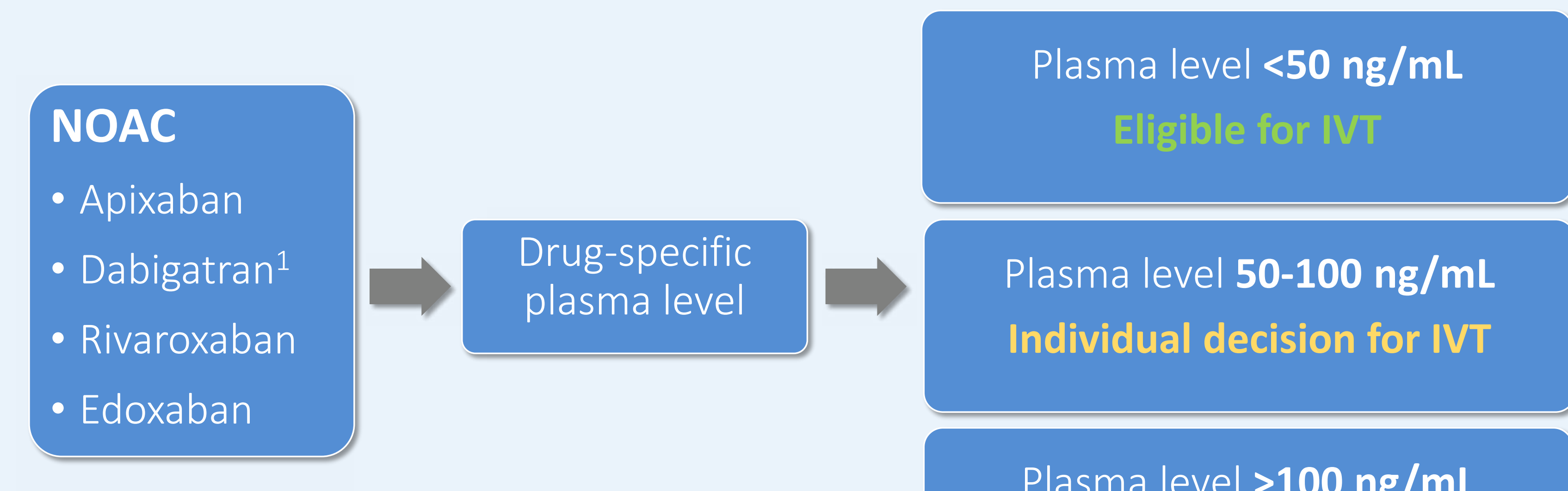

Plasma level $>\mathbf{1 0 0} \mathbf{n g} / \mathbf{m L}$ Figure 1: Standard operating procedure (SOP) for intravenous thrombolysis in acute ischemic stroke for patients on non-vitamin $\mathrm{K}$ oral anticoagulants (NOAC).

Patients on Dabigatran alternatively receive Idarucizumab (since available) to be considered eligible for IVT.

RESULTS: 523 patients ( 262 on NOAC and 261 on VKA) were included. Patients were on treatment with Apixaban (131), Rivaroxaban (85), Dabigatran (37), Edoxaban (9) or Phenprocoumon (261) within 48 hours prior to admission. The functional NOAC-plasma level was assessed in a total of $207(79.0 \%)$ patients (Figure 2 and 3 ).

$47(18.0 \%)$ of the VKA patients and $42(16.0 \%)$ of the NOAC patients underwent a recanalization therapy with IVT and/or EVT according to the standard operating procedure. Among the patients under VKA, 30 received IVT and 27 underwent EVT, including 10 who received both. 24 of the NOAC patients received IVT, 31 underwent EVT and 14 both. Successful mechanical recanalization ( $\mathrm{TICl} 2 \mathrm{~b}-3$ ) was achieved in 23 (85.2\%) VKA patients and 28 (90.3\%) NOAC patients. There were no differences in rates of major intracranial hemorrhage, which occurred in 2 (4.3\%) VKA and 2 (4.8\%) NOAC patients; $\boldsymbol{P}=0.908$. $11(25.0 \%)$ patients on VKA and 17 (41.5\%) patients on NOAC had a favorable outcome (mRS 0-2); $P=0.107$ (Figure 4).

CONCLUSION: The assessment of functional NOAC-plasma levels is feasible to support decisions on recanalization therapies. Under consideration of defined thresholds, no higher bleeding rates after treatment were observed when compared to established guidelines for patients under VKA.

\section{REFERENCES:}

1. Xian Y et al. Use of Intravenous Recombinant Tissue Plasminogen Activator in Patients With Acute Ischemic Stroke Who Take Non-Vitamin K Antagonist Oral Anticoagulants Before Stroke. Circulation. 2017;135(11):1024-1035.

Seiffge et al. Intravenous Thrombolysis in Patients with Stroke Taking Rivaroxaban Using Drug Specific Plasma Levels: Experience with a Standard Operation Procedure in Clinical Practice. J Stroke. 2017:19(3):347-355.

Rebello LC et al. Endovascular Treatment for Acute Ischemic Stroke in the Setting of Anticoagulation. Stroke. 2015;46(12):3536-9.

. Kepplinger et al. Standardized use of novel oral anticoagulants plasma level thresholds in a new thrombolysis decision making protocol. J Thromb Thrombolysis. 2016;41(2):293-300.

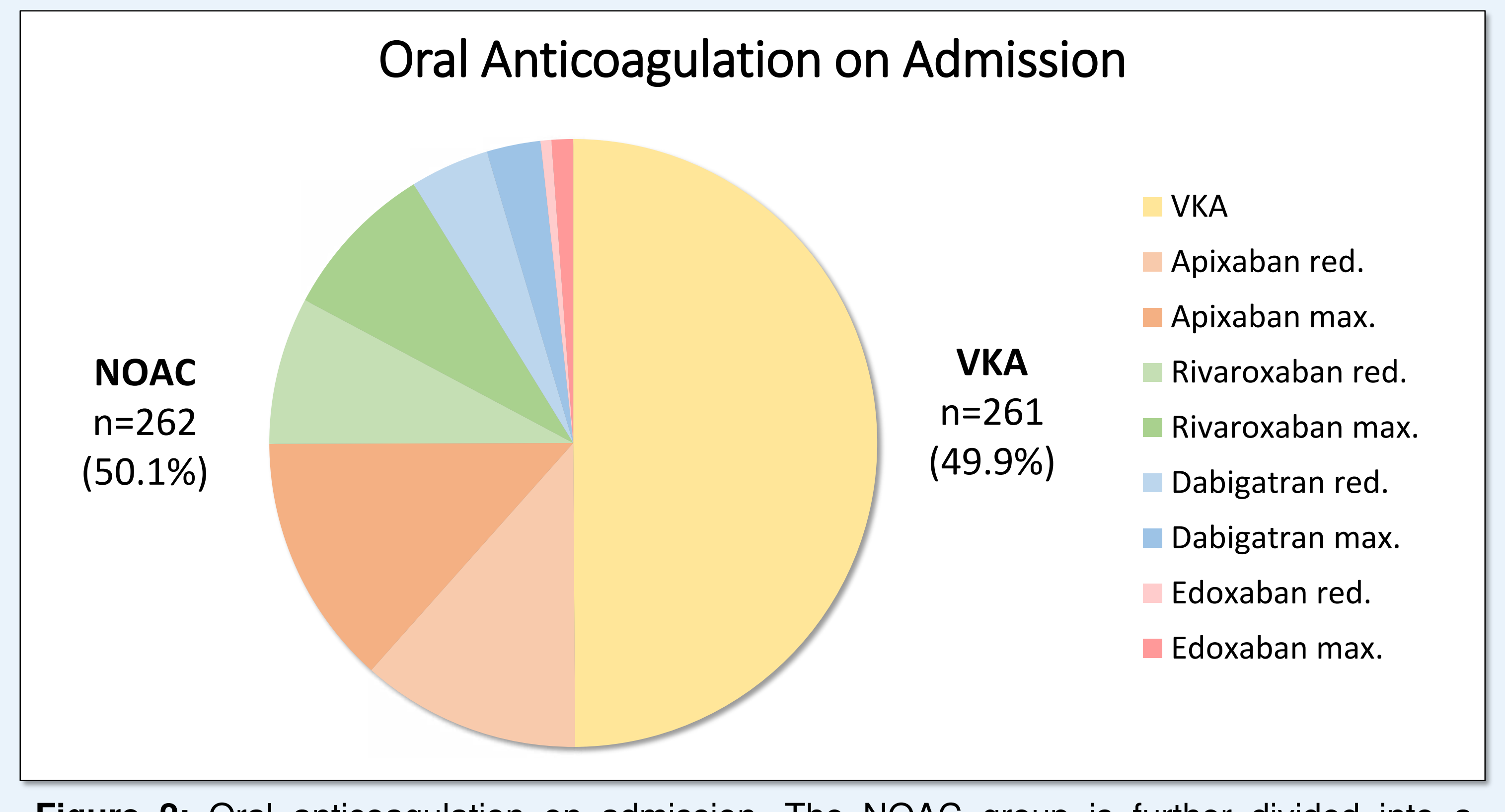

Figure 2: Oral anticoagulation on admission. The NOAC group is further divided into a reduced (red.) and maximum (max.) daily NOAC-dose.

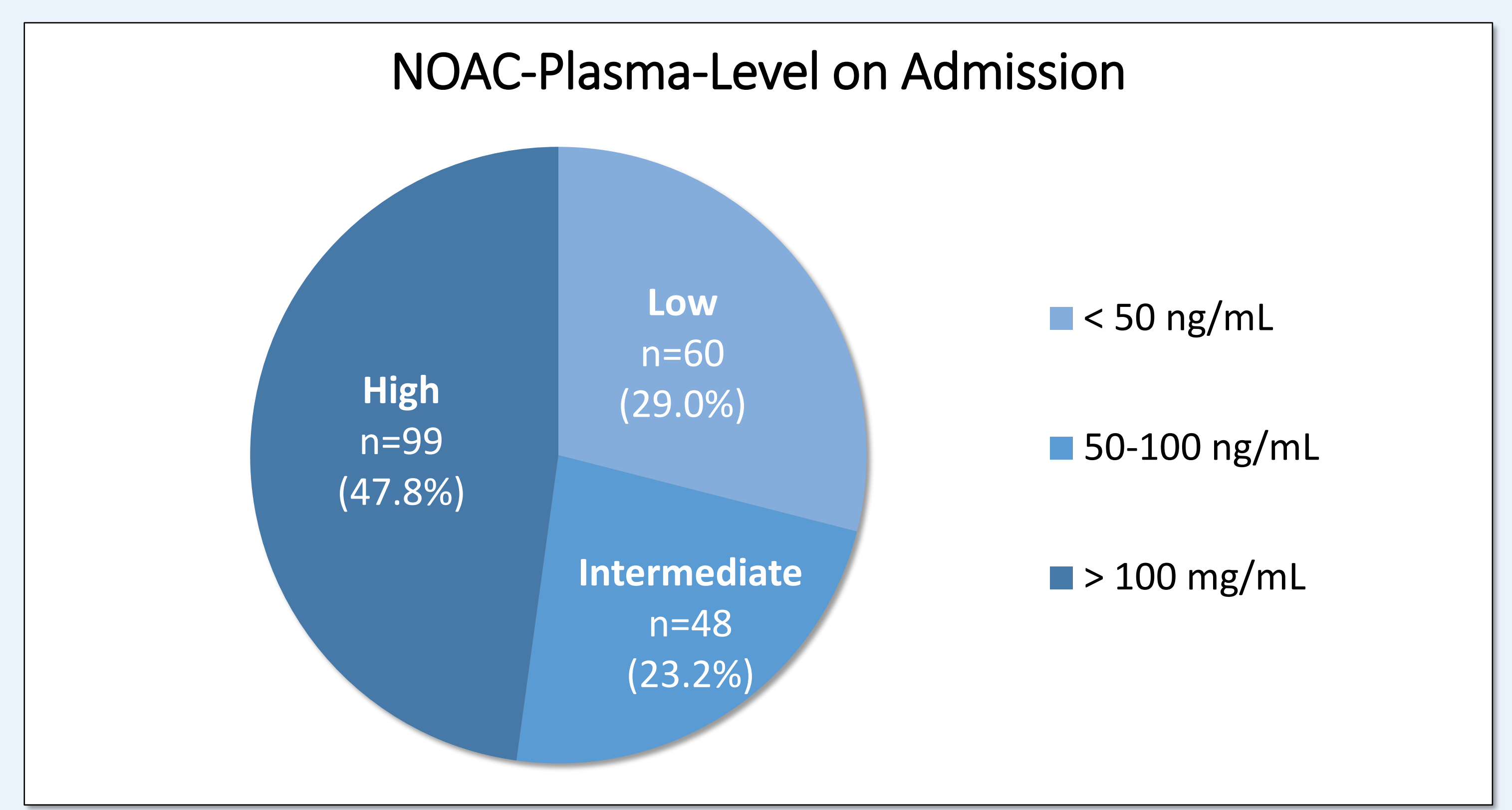

Figure 3: NOAC-Plasma-Level on admission.

\begin{tabular}{l|c|c|c|}
\multicolumn{1}{l|}{ Age (years) } & VKA (n=47) & NOAC (n=42) & PValue \\
\cline { 2 - 4 } Atrial fibrillation & $80(74-83)$ & $77(73-83)$ & 0.367 \\
\hline $\begin{array}{l}\text { Admission } \leq 4.5 \text { hrs } \\
\text { Large vessel occlusion }\end{array}$ & $42(89.4 \%)$ & $38(90.5 \%)$ & 0.862 \\
\hline $\begin{array}{l}\text { Coagulation } \\
\text { Phenprocoumon }\end{array}$ & $36(76.6 \%)$ & $31(73.8 \%)$ & 0.761 \\
\hline $\begin{array}{l}\text { Apixaban } \\
\text { Rivaroxaban }\end{array}$ & $39(83.0 \%)$ & $37(88.1 \%)$ & 0.495 \\
\hline $\begin{array}{l}\text { Dabigatran } \\
\text { Edoxaban }\end{array}$ & $\mathbf{4 7}(\mathbf{1 0 0 \% )}$ & - & \\
\hline NOAC max. daily dose & - & $\mathbf{1 8 ( 4 2 . 9 \% )}$ & \\
\hline
\end{tabular}

Table 1: Baseline characteristics of the IVT/EVT subgroup; number (\%) or median (IQR).

\begin{tabular}{|c|c|c|c|c|c|c|}
\hline & \multicolumn{2}{|c|}{$\begin{array}{l}\text { VKA }(n=47) \\
\text { INR }\end{array}$} & \multicolumn{4}{|c|}{$\begin{array}{c}\text { NOAC }(n=42) \\
\text { Drug-specific plasma-level }[\mathrm{ng} / \mathrm{mL}]\end{array}$} \\
\hline & $\begin{array}{l}\leq 1.7 \\
(n=36)\end{array}$ & $\begin{array}{l}>1.7 \\
(n=11)\end{array}$ & $\begin{array}{c}<50 \\
(n=23)\end{array}$ & $\begin{array}{l}50-100 \\
(n=11)\end{array}$ & $\begin{array}{l}>100 \\
(n=6)\end{array}$ & $\begin{array}{l}N / A \\
(n=2)\end{array}$ \\
\hline IVT & 29 & 1 & 21 & 3 & 0 & 1 \\
\hline EVT & 17 & 10 & 14 & 9 & 6 & 2 \\
\hline IVT+EVT & 10 & 0 & 12 & 1 & 0 & 1 \\
\hline $\mathrm{TICl} 2 \mathrm{~b}-3$ & 15 & 8 & 12 & 8 & 6 & 2 \\
\hline $\mathrm{ICH}_{\text {any }}$ & 6 & 7 & 5 & 3 & 0 & 0 \\
\hline $\mathbf{s I C H}_{\text {ECASS }}$ & 1 & 1 & 1 & 1 & 0 & 0 \\
\hline
\end{tabular}

Table 2: IVT/EVT subgroup. The number of patients which underwent a recanalization therapy, recanalization numbers and the number of intracranial hemorrhage are displayed.

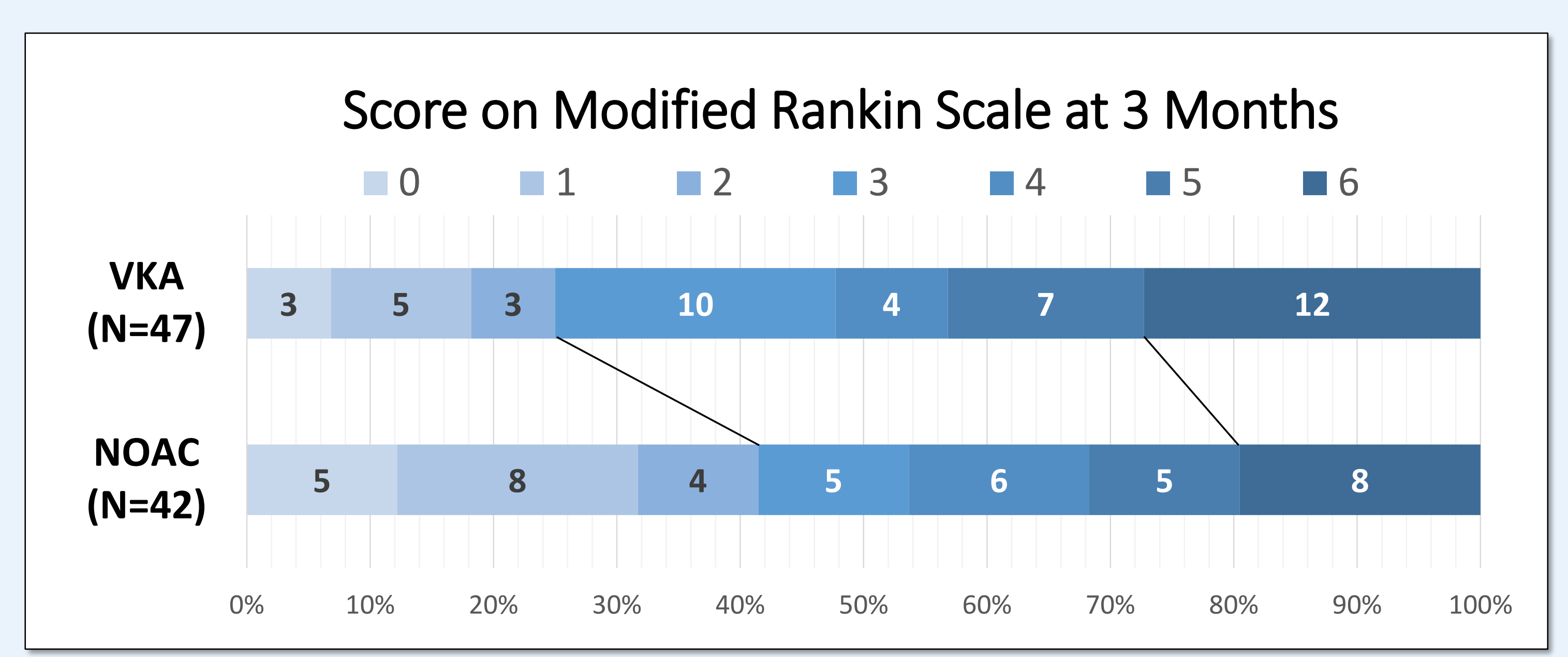

Figure 4: $m R S$ at 3 months in the IVT/EVT subgroup. 